\title{
Lung cancer stem cells and low-intensity laser irradiation: a potential future therapy?
}

\author{
Anine M Crous and Heidi Abrahamse
}

\begin{abstract}
Lung cancer is notably a significant threat when considering worldwide cancer-related deaths. Despite significant advances in treatment modalities, death rates as a result of cancer relapse remain high. Relapse can occur as a result of metastasis. Cancer stem cells (CSCs) have been implicated as an important contributory factor in the development of metastasis. CSCs have the same characteristics as normal stem cells; that is, they can proliferate indefinitely and are capable of both self-renewal and differentiating into specialized cells. The molecular and cellular characteristics of stem cells and CSCs are coded for by cell-specific genes, which can be analyzed by using molecular assays setting the standard to work from. Low-intensity laser irradiation (LILI) has been applied in the treatment of numerous diseases and pathological conditions. LILI has been shown to stimulate proliferation of cells, capillary growth, and cellular metabolism as observed by adenosine triphosphate activation. It has been shown, by using different dosing levels of LILI, to either stimulate or inhibit cellular functions. One treatment strategy used on cancer cells is photodynamic therapy (PDT), in which cancer cells are treated with a photosensitizer (PS) in combination with laser irradiation. PSs are nontoxic by themselves but, with light activation, cause reactive oxygen species generation, which causes cancer cell death. Cell-specific PSs are being developed for future cancer treatment. In this review, we look at the potential effects of LILI and PDT on lung CSCs.
\end{abstract}

\footnotetext{
* Correspondence: habrahamse@uj.ac.za

Laser Research Centre, Faculty of Health Sciences, University of Johannesburg, P.O. Box 17011, Doornfontein 2028, South Africa
}

\section{Introduction}

Cancer is a disease that is characterized by the uncontrollable growth of cells leading to tumor formation [1]. Lung cancer is one of the prime causes of cancer mortality worldwide because of its metastatic properties [2] and potential for relapse. A plausible reason for relapse is that cancer stem cells (CSCs), found in solid tumors, may contribute to metastatic processes such as migration, resistance to current treatment modalities, including chemo- and radiation therapy, and resistance to cell death in comparison to normal cell death rates [3]. CSCs are thought to develop from normal stem cells (SCs) which have undergone several genetic mutations [1]. Therefore, CSCs have shown similar SC characteristics such as self-renewal and differentiation potential [3]. As a result of current treatments failing to target CSCs [4], novel therapies such as low-intensity laser irradiation (LILI) and photodynamic therapy (PDT) are being investigated as novel therapeutic applications [5,6]. These implementations are due to evidence suggesting that laser photons stimulate a significant amount of cellular biological effects [7] and PDT, which is the use of a photosensitizer (PS) along with LILI, results in the generation of reactive oxygen species (ROS) which are toxic to cancer cells and evidently lead to cellular death [6]. The effects of LILI and PDT on lung CSCs will be addressed in this review.

\section{Lung cancer}

Accumulated genetic modifications in lung cells cause cell irregularities such as metastatic potential, tissue invasion, and uncontrolled cell growth [1]. These modifications occur as a result of genetic sequence or epigenetic alterations, in which modification is manifested in gene activation or expression of proteins $[8,9]$. The tumor formation from the uncontrolled cell growth contains a cell population that is heterogeneous. These cells have various cellular characteristics and functions assisting tumor formation [1].

Lung cancer is the leading cause of cancer deaths worldwide, and more than $50 \%$ of lung cancer-related deaths 
are caused in people who do not smoke. Recent studies suggest a genetic mutation in the epidermal growth factor gene as well as environmental factors to be the causative agents [2]. Lung disease symptoms that can overlap with lung cancer include excessive coughing, chest pain and discomfort, and weight loss, although it has been noted that in some cases the metastatic disease may present as asymptomatic. Typical diagnostic tools for lung cancer include an x-ray or computed tomography scan and conformational biopsy [2].

The two types of lung cancer associated with smoking are small cell lung cancer (SCLC) and non-small cell lung cancer (NSCLC). SCLC is characterized by very rapid tumor growth and is a more homogenous disease with a predisposition to metastasize. The overall prognosis remains poor, although it is recognized as a chemo-sensitive disease. Patients with NSCLC account for $70 \%$ to $80 \%$ of lung cancer cases. When the disease is not metastasizing, surgery is the main therapy. Although treatment has progressed over the years, the survival rate is less than 5 years from time of diagnosis in $15 \%$ of patients, but $1 \%$ of metastatic patients will survive. Focus should be emphasized not only on smoking cessation and early detection for prognostic improvement but also on researching the genetic aspects of lung cancer. Novel therapies and treatments like LILI and PDT could improve prognosis and survival rates $[2,10]$.

\section{Stem cells}

SCs are cells that are not specialized and have two significant properties: namely, the capability to differentiate into other cells and to self-renew through cell division. SCs can have different differentiation potentials, which affect their potency. Totipotent SCs can differentiate into any type of cell, pluripotent SCs can differentiate into all three germinal layers (mesoderm, ectoderm, and endoderm), and multipotent SCs will develop into several cell types. SCs can undergo either symmetrical division in which two daughter $\mathrm{SCs}$ are produced or asymmetrical division in which one daughter $\mathrm{SC}$ is produced as well as a specialized cell $[11,12]$.

As SCs have these unique regenerative abilities, they offer new potential for treating diseases. Research studies of SCs have enabled scientists to manipulate them in the laboratory for drug screening and to develop model systems to study normal and abnormal cell models. However, significant research is required on these cells to potentiate cell-based therapy and treatment [12]. SCs are currently being investigated for a multitude of biological and tissue-engineering applications.

\section{Embryonic stem cells}

Embryonic stem cells (ESCs) are derived mostly from blastocysts which have been created in vitro [13]. They can be passaged several times without differentiating. When the chromosomes of these cells are studied, they appear normal. Even after prolonged proliferation in their undifferentiated state, ESCs can reproduce each of the three cell types found in the embryo: pluripotent, multipotent, and unipotent SCs $[11,13]$. ESCs have specific properties to which they adhere, and these properties are measured through characterization, namely (a) culturing and subculturing the SCs to find out whether they remain undifferentiated; (b) testing for the presence of transcription factors which appear in undifferentiated cells; (c) testing for specific cell surface markers occurring in undifferentiated cells; (d) examination of chromosomal stability; (e) testing reculturing capability after freezing, thawing and seeding them again; and (f) identifying pluripotency in the SCs [12].

\section{Adult stem cells}

Adult stem cells (ASCs) are isolated from the somatic tissue of adult organisms. They can be found in various organs of the body, including the bone marrow, gastrointestinal tract, pancreas, and liver $[14,15]$. ASCs reside in an SC niche, where they produce cell types of the cell tissue that they reside in. Research has shown that it is possible to stimulate ASCs to differentiate into cells of interest by genetic manipulation or manipulation of its differentiation pathway. This knowledge can offer potential reprograming of available cells into other cells that are damaged or have been lost due to disease. SC differentiation is triggered by the need for tissue maintenance due to injury or disease. ASCs can be characterized by generating a cell line of genetically identical cells that upon induction to differentiation will give rise to all the different cells in that specific tissue [11,12].

\section{Cancer stem cells}

CSCs can be defined as cells within a tumor that can selfrenew and result in the heterogeneous lineages of cancer cells in a tumor [16]. CSCs are referred to as tumorinitiating cells (TICs) as the cancer could have formed from stem, progenitor, or differentiated cells [1]. These cells possess stem-like characteristics reminiscent of a normal SC. Cancer cells that metastasize portray the classic properties of SCs [3]. CSCs have been isolated and characterized from tumor masses and these TICs have since been characterized by using cell-surface protein markers [11]. The similarities between TICs or CSCs and SCs leads to the hypothesis as to whether CSCs arise from SCs, progenitor cells, or differentiated cells present in adult tissues. The molecular pathways that maintain 'stem-ness' in SCs are also active in numerous cancers [1]. This similarity has initiated the proposition that cancers may arise when there is a mutation in an SC causing abnormal cell expansion [1].

Metastasis is a complex multi-step process and CSCs support it by detaching from the original tumor, migrating through the blood or lymphatic system to a new site, and lodging into the surrounding tissue forming micro- 
metastases. The cells then develop blood supplies and grow to form macroscopic and clinically relevant metastases. According to previous studies, it is suggested that a small, and most likely specialized, subset of cancer cells drive the spread of disease to distant organs [17]. SCs and metastatic cancer cells share metastatic functions. They both require a specific microenvironment or niche for growth and protection, the use of specific cellular pathways for migration, enhanced resistance to cell death, and an increased capacity for drug resistance. Evidence suggests that these properties apply to CSCs as well [3], making them a primary cause for cancer relapse.

Researchers and drug developers are directing research toward the paradigm of developing agents that target molecules implicated in cancer pathways as well as the cell itself as this selective approach has been shown to be promising. Therefore, if the CSC hypotheses are proved to be correct, strategies designed to target CSCs selectively could prevent these TICs from germinating and spreading [1]. Here, LILI could be implicated as a treatment methodology, in which PDT is used to target CSCs specifically with a PS and laser irradiation.

\section{Lung cancer stem cells}

Patients with SCLC frequently present with metastases regardless of the primary tumor size. This suggests that early-disseminated disease in patients with lung cancer is due to enrichment of CSCs in these tumors. Lung cancer is a group of neoplastic cells, which can be phenotypically diverse. Lung CSCs have been identified in lung cancer and have been characterized [18].

CSCs with SC-like phenotypes are derived from normal SCs or differentiated cells that underwent deregulation of the fundamental characteristic of SCs, which divide into normal SCs (self-renew) and differentiate into specialized cells. This is due to asymmetric and symmetric divisions in which there is an error in the cell cycle. This characteristic applies not only to lung CSCs but to other CSCs as well. Pathways such as the Notch, Hedgehog $(\mathrm{HH})$, and Wnt define normal SCs and guide the behavior of normal pulmonary precursors within several different lineages. Abnormal signaling in these pathways may cause lung cancer arising from inappropriate expansion of pulmonary SCs developing into CSC lineages [19].

Previous studies performed on mice have identified SC niches in the lung, and these niches may be targeted for cancer initiation and promotion [20]. SC niches maintain the epithelial differentiation of the bronchi [21]. Found in these niches are bronchio-alveolar SCs that co-express Clara, alveolar cell markers, and SC markers. Along with the expression of oncogenic k-ras, the bronchio-alveolar SCs show an increase in proliferation, indicative of their characteristics as compared with differentiated alveolar cells which proliferate at a different exponential rate. This manifestation is similar to that of the development of bronchio-alveolar SCs in adenocarcinoma, as a cause of SCs rapidly dividing, losing their normal SC characteristics and developing into CSCs [22].

\section{Cancer stem cell markers}

In addition to the genes involved in the Notch, Wnt, and $\mathrm{HH}$ pathways, there are numerous genetic markers associated with CSCs. One is the Oct-4 gene (OCT3 or POU5F1), which is a transcription factor that maintains ESC pluripotency [23]. Oct-4 may be regulated by the Wnt pathway and can re-program somatic cells biologically, dedifferentiating them back into SCs [24].

It has been suggested that miRNAs are vital regulators of SC differentiation, self-renewal, and division as indicated by studies completed on mice [25]. miRNA-155 is involved in normal human lung differentiation [26]. Work from the National Cancer Institute has shown that high hsa-mir-155 and low hsa-let-7a-2 expression have been associated with poor prognoses in lung cancer [27].

Lung CSCs can be identified and characterized by using cell surface markers. Tumors are initially thought of as consisting of a single type of tissue of homogenous cells. However, they are thought to be heterogeneous on a smaller scale, phenotypically differing by their surface marker. They vary in the capacity for self-renewal and differentiation. Experimental evidence showed that different cancer cells share cell surface markers with other cancerous cells and several SCs [28]. Table 1 lists known or potential SC markers in lung cancer [18].

Validation of CSCs based on expression of cell surface markers is difficult when expanding the cells in vitro as the cultured cells may lose their original phenotype through differentiation due to external factors like growth media impacting on them. Thus, culturing the cells based on their specific SC markers results in the reconstitution of the original phenotype and loss of SC enrichments; that is, the SCs may differentiate into specialized cells. One method of maintaining the SC markers is by plating individual cells in semi-solid media, in the presence of epidermal growth factor and basic fibroblast growth factor, which will make the cells resultantly grow in spheroid structures, preserving the $\mathrm{SC}$ markers. Further characterization then requires dissociation into single-cell suspensions $[18,38]$.

Further studies on developing methods that allow expansion of CSCs in vitro are critical for their characterization and development of SC-targeted therapies and treatment [18]. In vivo validation can be achieved by implanting tumor cells into a host where tumor growth and drug response can be measured [39]. Visualization of tumor growth is achieved best when using fluorescent markers. Thus far, this method of implanting tumor cells into a host is the most effective model for testing novel cancer stem celltargeted therapies [18]. The disadvantage of this method is 
Table 1 Cellular markers that may contribute to lung cancer stem cell properties

\begin{tabular}{|c|c|c|c|c|c|}
\hline \multirow[t]{2}{*}{ Marker } & \multirow[t]{2}{*}{ Name } & \multirow[t]{2}{*}{ Cellular function } & \multirow[t]{2}{*}{ Ligand } & \multicolumn{2}{|c|}{$\begin{array}{l}\text { Cancer stem cell } \\
\text { marker }\end{array}$} \\
\hline & & & & Lung & Other \\
\hline CD44 & Pgp-1 & Hyaluronic acid receptor & $\begin{array}{l}\text { Hyaluronic acid and } \\
\text { hyaluronate-interacting growth } \\
\text { factors, osteopontin }\end{array}$ & NSCLC & $\begin{array}{l}\text { Hematopoietic, } \\
\text { breast }\end{array}$ \\
\hline CD133 & Prominin-1 & $\begin{array}{l}\text { Modulator of intracellular accumulation of exogenous } \\
\text { compounds (transferin-CD133-iron network) cell metabolism } \\
\text { [29] Neurotrophic receptor RET tyrosine kinase expression [30] }\end{array}$ & $\begin{array}{l}\text { No natural ligand identified } \\
\text { [31] }\end{array}$ & $\begin{array}{l}\mathrm{NSCLC} \\
{[32]}\end{array}$ & $\begin{array}{l}\text { Brain, colon, } \\
\text { pancreas }\end{array}$ \\
\hline CD117 & $\begin{array}{l}\text { Stem cell } \\
\text { factor receptor }\end{array}$ & Growth factor receptor & Stem cell factor & $\begin{array}{l}\text { SCLC } \\
{[33]}\end{array}$ & Hematopoietic \\
\hline CD87 & $\begin{array}{l}\text { Urokinase } \\
\text { plasminogen } \\
\text { activator }\end{array}$ & UPA receptor & UPA & $\begin{array}{l}\text { NSCLC/ } \\
\text { SCLC } \\
{[34]}\end{array}$ & Unknown \\
\hline SP & $\begin{array}{l}\text { Side } \\
\text { population }\end{array}$ & Drug resistance & EGFR [35] TRAIL [36] & $\begin{array}{l}\mathrm{SC} / \\
\mathrm{NSCLC}\end{array}$ & $\begin{array}{l}\text { Hematopoietic, } \\
\text { brain, breast }\end{array}$ \\
\hline $\mathrm{ALDH}$ & $\begin{array}{l}\text { Aldehyde } \\
\text { dehydrogenase }\end{array}$ & Alcohol metabolism & Acetaldehyde & $\begin{array}{l}\text { NSCLC } \\
{[37]}\end{array}$ & $\begin{array}{l}\text { Hematopoietic, } \\
\text { breast, prostate }\end{array}$ \\
\hline
\end{tabular}

EGFR epidermal growth factor receptor, NSCLC non-small cell lung cancer, SC stem cell, SCLC small cell lung cancer, TRAIL tumor necrosis factor-related apoptosisinducing ligand, UPA urokinase plasminogen activator. Modified from [19].

that it will be ethically unacceptable to inject cancer cells into a human being; therefore, in vitro models need to be developed. Such models can be developed by using CSCs where they are cultured and monitored for tumor formation and cellular responses to treatment such as LILI.

\section{Low-intensity laser irradiation}

A laser is defined as any device using controlled stimulated emission by producing or amplifying electromagnetic radiation in the wavelength range from $180 \mathrm{~nm}$ to $1 \mathrm{~mm}$ [40]. Laser power is measured in watts or milliwatts. The output measurement of a laser is proportional to power density. Where power density or light intensity is measured in watts per centimeter squared or milliwatts per centimeter squared, this includes the area of the object exposed to laser light. Wavelength $\lambda$ (lambda), which is expressed in nanometers, is the distance between two peaks of a light wave [41]. When a laser emits light at a constant intensity, it has a continuous wave emission, whereas pulsed light will have varying intensity. To calculate intensity of a pulsed laser, the average between the pulse peak of the wave output and zero is used. Continuous wave lasers use output power [42]. The effects that laser irradiation may have on tissue may vary according to the wavelength and power density used [43].

Low-intensity lasers or low-power lasers have become important medical tools used for therapeutic applications. LILI is a form of phototherapy in which monochromatic light is used on biological tissue, creating a biomodulative effect within that tissue. The biomodulative effect can be stimulatory or inhibitory, either of which can be used in treatment, depending on the required effect. LILI is nonthermic [44] and uses light at a wavelength of 630 to 905 nm [45]. Helium-neon and diode lasers are some of the therapeutic lasers that are routinely used.

\section{Uses of low-intensity laser irradiation}

The reported biomodulative effects of LILI on tissue are caused by the energy delivered through the light irradiation which has a direct effect eliminating thermal effects. Significant biological effects noted to be generated include proliferation, collagen synthesis, and release of growth factors from cells when treated with LILI. It enhances and stimulates these cellular effects at certain wavelengths and fluencies [7] while the mechanism of biostimulation by LILI occurs at the mitochondrial level since it contains most of the cellular chromophores [46]. One hypothesis explaining the mechanism of photostimulation is that the energy is absorbed by intracellular chromophores and is converted into metabolic energy (that is, the respiratory chain, which produces changes in the redox status in the mitochondria) (Figure 1). Activation of the electron transport chain results in an increase in the electrical potential across the mitochondrial membrane or an increase in the ATP pool. cAMP, a molecule derived from ATP, is important in many biological processes. Since the cAMP system has been demonstrated to control the biosynthesis of DNA and RNA, LILI can indirectly lead to the activation or inhibition of nucleic acid synthesis [47].

Irradiation or photostimulation is used in a variety of in vitro models such as cellular cultures as it provides us with molecular-scale answers. These models are less destructive, and biopsies are avoidable. In a variety of cell 


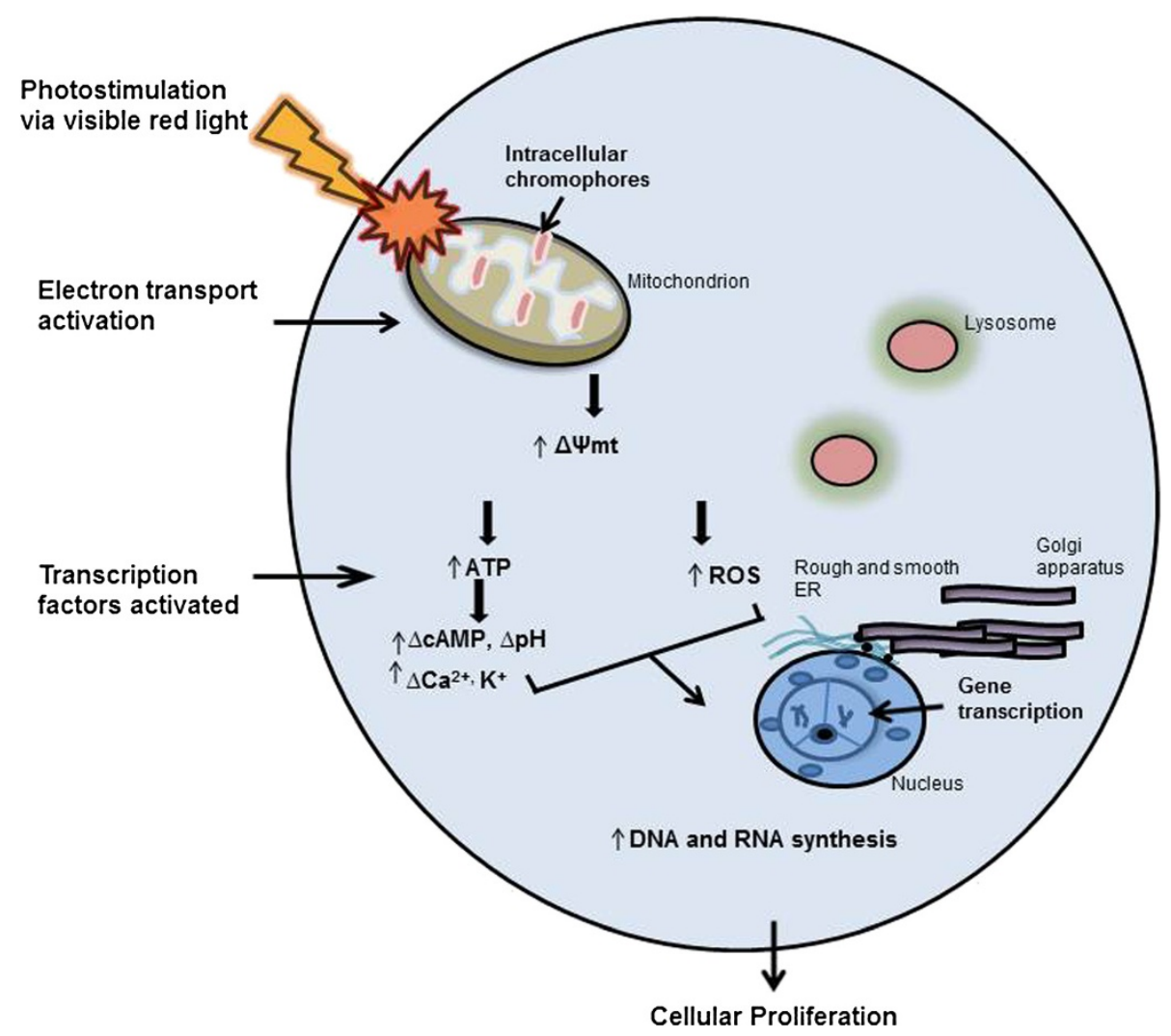

Figure 1 Proposed mechanism of photostimulation. Energy is absorbed from the laser light by the intracellular chromophores and converted into metabolic energy, which in turn can lead to cellular proliferation as a result of cellular responses being activated via photostimulation. $\Delta \Psi$ mt, the electrical potential across the mitochondrial membrane; ER, endoplasmic reticulum; ROS, reactive oxygen species.

cultures treated with LILI, results have indicated an increase in the stimulation of proliferation. Irradiation is performed on humans where qualitative evaluation of wound healing is monitored; it has been shown to have beneficial effects such as healing diabetic and other types of ulcers. LILI has been used in vivo as thus far it has shown no known side effects when used according to standard operating procedures [48].

Previous studies using LILI have shown either a proliferatory effect or an inhibitory effect, depending on the energy level used [49]. In a 2011 study by AlWatban and Bernard [5], normal and malignant cell lines consisting of embryonic (3 T3, CCl-226 mouse embryonic fibroblast), human skin fibroblasts, Chinese hamster ovary cells, and neoplastic cells (RIF-1 and EMT-6) were treated with LILI in order to determine the laser dose for the different stimulatory or inhibitory effects while all cell lines were kept at similar conditions. The authors concluded that there is dose dependency for cell growth to laser treatments and that the extent of cellular proliferation is influenced by the type of cells involved. Normal cells showed biostimulation exploiting SC expansion and differentiation. Malignant cells also indicated an increase in proliferation, suggesting that LILI has the capability to induce further cell growth of neoplasms; nonetheless, LILI also induced cell bioinhibition at higher energy outputs, implicating the use of LILI to destroy malignant cells. This study showed that the optimum biostimulatory dose at a wavelength of 632.8 $\mathrm{nm}$ is at $180 \mathrm{~mJ} / \mathrm{cm}^{2}$ and bioinhibitory doses were from 420 to $600 \mathrm{~mJ} / \mathrm{cm}^{2}$ using cumulative doses [5]. Different laser parameters apart from the ones used in previous studies are still recommended for the clonal expansion and differentiation of SCs [5] and CSCs. Cytochrome $c$ oxidase is believed to be the primary cellular chromophore to absorb low levels of red and near-infrared light. It is located in the inner mitochondrial membrane and is an integral part of the electron transport chain associated with oxidative phosphorylation and ATP production. Absorbing this energy can cause an increase in ATP production and evidently leads to cell proliferation and migration [50].

LILI has been used clinically for wound and burn healing and treating myocardial infarction and stroke, diabetic angiopathy, and neuropathy and the reduction of atherosclerotic plaque formation by increasing 


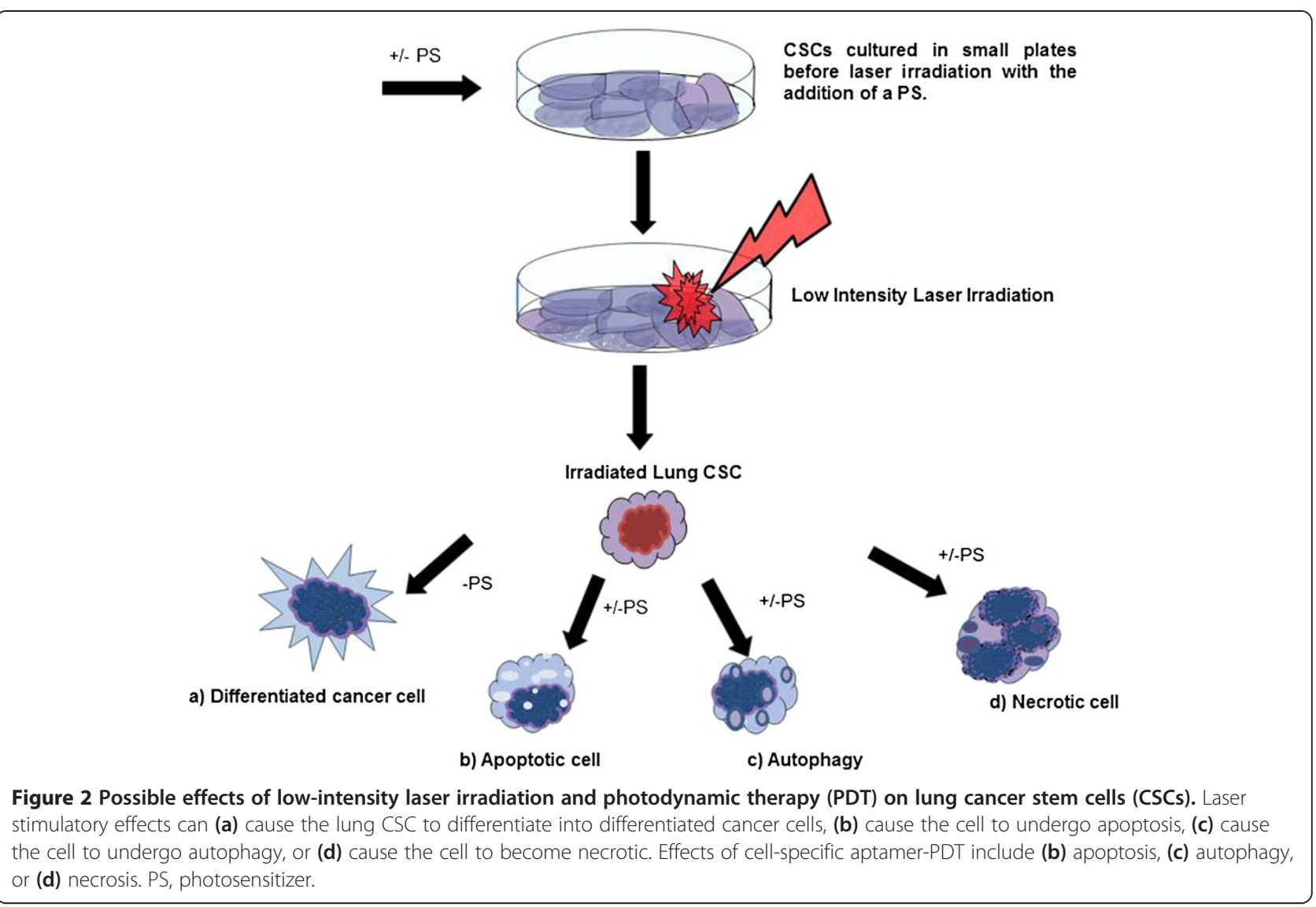

microcirculation [51]. Studies show that LILI has positive effects on irradiated cells and tissues, such as increased formation of mRNA and protein secretion. There is also stimulation of calcium influx and mitosis rate, activation of inactive enzymes, including ATPase (adenosine triphosphatase), and photosensitized formation of ROS [52]. Laser photons are absorbed by cytochromes and porphyrins within the mitochondria. Singlet oxygen is produced also, forming proton gradients across the mitochondrial membrane, increasing ATP and DNA production [53].

Researchers have found, in contrast to the above effects, that LILI can be damaging or even destructive. Helium-neon laser irradiation produced degenerative effects on bovine oocytes, namely changes to both the cytoplasm, which was heterogeneous, and the chromosomes that were unevenly dispersed when compared to un-irradiated control oocytes [54]. However, the true effect of LILI on cell proliferation is controversial because of conflicting reports on the effects of visible light on cells in culture [55] and this could be because LILI has different effects at different energy outputs. This emphasizes the need for cellular research into laser biology, especially when considering cancer as one of the important targets for using laser as a treatment.
Research needs to be directed toward CSCs in laser biology as CSCs are potentially the cause for relapse and the effects of LILI on lung CSCs have yet to be elucidated.

The current cancer treatment using lasers is PDT. PDT involves administration of a PS either topically or systemically followed by visible light from a laser illuminating the target area that then triggers oxidative stress in the cell, leading to cellular death [6]. A number of possible PSs have been studied for the treatment of cancers. A PS is administered and laser light is applied to the target area at the appropriate wavelength, and the PS is then activated, causing it to generate ROS by reacting with the oxygen present in the cancer cell and this in turn causes cell death [56]. The inactive PS is nontoxic and is activated by a specific wavelength matching its absorbance spectrum. The PS is excited to an excited singlet state where afterward it relaxes into a longer-lasting triplet state of excitation. ROS are formed in the triplet state, whereby the molecules exchange electrons or hydrogen atoms with nearby molecules (type 1 photochemical reaction) or the PS transfers energy to ground-state molecular oxygen (type 2 photochemical reaction). Both photochemical reactions result in ROS formation, causing oxidative stress which leads to DNA damage after PDT treatment [6]. The PS is 
absorbed only by cancerous cells; the reason is that cancer cells have a rapid metabolic rate and the cells' physiological properties cause the PS to be absorbed and retained [57]. CSCs can be targeted in the same way as cancer cells by developing a PS targeted specifically to the CSC of interest by creating an effective molecular platform. This can be executed by following the same program used in previous experiments where researchers have developed a strategy which they call cell-SELEX (Systematic Evolution of Ligands by Exponential Enrichment), whereby they develop aptamers which are oligonucleic acid or peptide molecules that bind to a specific target molecule. Aptamers are selected by using complete and viable cells from which the aptamer will recognize that cell's specific protein membrane with elevated selectivity and outstanding affinity [58]. Other means of targeting cancer cells could be by using molecular beacons that work by illuminating a particular cell target. To identify the cellular and metabolic markers specific to the cell of interest, the beacons can be used in conjunction with near-infrared fluorescence imaging. These illumination beacons can be used either for imaging or as targetspecific aptamers for PDT, where the laser is guided by the fluorescing beacon attached to the affected sites, killing the cancerous cells by using the light-activated phototoxic properties of the porphyrin-based dye [59].

Possible effects of LILI can include increased proliferation, which in turn can cause the lung CSCs to differentiate into adult lung cancer cells, which will promote tumor formation or CSCs can undergo apoptosis, autophagy, or necrosis, whereby they die, promoting cancer death. In conjunction with a cell-specific aptamer-PS (PDT), the CSC is targeted by the PS and when irradiated will undergo apoptosis or necrosis as a result of ROS damaging the cells (Figure 2).

\section{Conclusions}

It is plausible, when considering the bioinhibitory effect of LILI on neopleastic cells as demonstrated by AlWatban and Bernard [5], to deduce that the same inhibitory effect may be demonstrated in CSCs. Apoptosis or necroptosis would be the desired cell death mechanism induced as it can be controlled through different cellular pathways. The development of cellular therapy using CSCs can be advanced by studying the mechanisms by which these cells differentiate and proliferate. With the use of LILI as a treatment on lung CSCs, the results obtained through cellular responses and characterization could lead to the answer of whether LILI alone at a specific wavelength or energy output or in conjunction with a PS inhibits these cells. If so, LILI can be used as a treatment that can prevent cancer relapse or as a therapy for cancer patients who have relapsed because of CSCs. Consideration also needs to be given to specific
aptamer-PDT, as it has already been established that PDT works on cancer cells and is currently being used as a cancer treatment. In conclusion, it would be advantageous to develop a specific aptamer-PS targeting CSCs, destroying them and thereby preventing cancer relapse.

\section{Abbreviations \\ ASC: Adult stem cell; CSC: Cancer stem cell; ESC: Embryonic stem cell; HH: Hedgehog; LILI: Low-intensity laser irradiation; NSCLC: Non-small cell lung cancer; PDT: Photodynamic therapy; PS: Photosensitizer; ROS: Reactive oxygen species; SC: Stem cell; SCLC: Small cell lung cancer; SELEX: Systematic Evolution of Ligands by Exponential Enrichment; TIC: Tumor-initiating cell.}

\section{Competing interests}

The authors declare that they have no competing interests.

\section{Published: 23 Oct 2013}

\section{References}

1. Goldthwaite CA: Are stem cells involved in cancer? [http://stemcells.nih gov/info/2006report/2006chapter9.htm]

2. Hong KW, Tsao AS: Lung carcinoma. [http://www.merckmanuals.com]

3. Croker AK, Allan AL: Cancer stem cells: implications for the progression and treatment of metastatic disease. J Cell Mol Med 2008, 12:374-390.

4. Naujokat C, Laufer S: Targeting cancer stem cells with defined compounds and drugs. J Cancer Res Updates 2013, 2:36-67.

5. AL-Watban FAH, Bernard LA: Laser biomodulation of normal and neoplastic cells. Lasers Med Sci 2011, 27:1039-1043.

6. El-Hussein A, Harith $\mathrm{H}$, Abrahamse $\mathrm{H}$ : Assessment of DNA damage after photodynamic therapy using a metallophthalocyanine photosensitizer. International Journal of Photoenergy 2012, 2012:1-10. doi:10.1155/2012/ 281068.

7. Sommer AP, Pinheiro AL, Mester AR, Franke RP, Whelan HT: Biostimulatory windows in low intensity laser activation: lasers, scanners and NASA's light-emitting diode array system. J Clin Laser Med Surg 2001, 19:29-34.

8. Feinberg AP, Ohlsson R, Henikoff $S$ : The epigenetic progenitor origin of human cancer. Nat Rev Genet 2006, 7:21-33.

9. Jones PA, Baylin SB: The epigenomics of cancer. Cell 2007, 128:683-692.

10. Stupp R, Monnerat C, Turrisi AT, Perry MC, Leyvraz S: Small cell lung cancer: state of the art and future perspectives. Lung Cancer 2004, 45:105-111.

11. National Institutes of Health, U.S. Department of Health and Human Services Stem Cell Basics. [http://stemcells.nih.gov/info/basics/basics]

12. Kochar PG: What are stem cells? [http://www.csa.com/discoveryguides/ stemcell/editor.php]

13. Thomson JA, Itskovitz-Eldor J, Shapiro SS, Waknitz MA, Swiergiel JJ, Marshall VS, Jones JM: Embryonic stem cell lines derived from human blastocysts. Science 1998, 282:1145-1147.

14. Bio-Rad Laboratories, Inc: Stem cell basics for life science. [http://www.biorad.com]

15. Yalniz M, Pour PM: Are there any stem cells in the pancreas? Pancreas 2005, 31:108-118.

16. Clarke MF, Dick JE, Dirks PB: Cancer stem cells - perspectives on current status and future directions: AACR Workshop on cancer stem cells. Cancer Res 2006, 66:9339-9344.

17. Luzzi KJ, MacDonald IC, Schmidt EE: Multistep nature of metastatic inefficiency: dormancy of solitary cells after successful extravasation and limited survival of early micrometastases. Am J Pathol 1998, 153:865-873.

18. Pine SR, Marshall B, Varticovskia L: Lung cancer stem cells. Dis Markers 2008, 24:257-266.

19. Natarajan TG, FitzGerald KT: Markers in normal and cancer stem cells. Cancer Biomark 2007, 3:211-231.

20. Giangreco A, Reynolds SD, Stripp BR: Terminal bronchioles harbor a unique airway stem cell population that localizes to the bronchoalveolar duct junction. Am J Pathol 2002, 161:173-182.

21. Hong KU, Reynolds SD, Watkins S, Fuchs E, Stripp BR: Basal cells are a multipotent progenitor capable of renewing the bronchial epithelium. Am J Pathol 2004, 164:577-588. 
22. Kim CF, Jackson EL, Woolfenden AE, Lawrence S, Babar I, Vogel S, Crowley $D$, Bronson RT, Jacks T: Identification of bronchioalveolar stem cells in normal lung and lung cancer. Cell 2005, 121:823-835.

23. Pesce M, Scholer HR: Oct-4: gatekeeper in the beginnings of mammalian development. Stem Cells 2001, 19:271-278.

24. Grinnell KL, Yang B, Eckert RL, Bickenbach JR: De-differentiation of mouse interfollicular keratinocytes by the embryonic transcription factor Oct-4. J Invest Dermatol 2007, 127:372-380.

25. Hatfield S: Ruohola-Baker $\mathrm{H}$ : microRNA and stem cell function. Cell Tissue Res 2008, 331:57-66.

26. Georgantas RW III, Hildreth R, Morisot S, Alder J, Liu CG, Heimfeld S, Calin GA, Croce CM, Civin Cl: CD34+ hematopoietic stem-progenitor cell microRNA expression and function: a circuit diagram of differentiation control. Proc Natl Acad Sci U S A 2007, 104:2750-2755.

27. Yanaihara N, Caplen N, Bowman E, Seike M, Kumamoto K, Yi M, Stephens RM, Okamoto A, Yokota J, Tanaka T, Calin GA, Liu CG, Croce CM, Harris CC: Unique microRNA molecular profiles in lung cancer diagnosis and prognosis. Cancer Cell 2006, 9:189-198.

28. Liu J, Jiang G: CD44 and hematologic malignancies. Cell Mol Immunol 2006, 3:359-365.

29. Bourseau-Guilmain E, Griveau A, Benoit J-P, Garcion E: The importance of the stem cell marker prominin-1/CD133 in the uptake of transferrin and in iron metabolism in human colon cancer Caco-2 cells. PLoS One 2011, 6:e25515.

30. Takenobu H, Shimozato O, Nakamura T, Ochiai H, Yamaguchi Y, Ohira M, Nakagawara A, Kamijo T: CD133 suppresses neuroblastoma cell differentiation via signal pathway modification. Oncogene 2011, 30:97105.

31. Sun J, Zhang C, Liu G, Liu H, Zhou C, Lu Y, Zhou C, Yuan L, Li X: A novel mouse CD133 binding-peptide screened by phage display inhibits cancer cell motility in vitro. Clin Exp Metastasis 2012, 29:185-196.

32. Virginia T, Rosa C, Renato F, Donatella M, La Roccae A, Giuseppe V, Gaetano $R$, Giuseppe P: The role of CD133 in the identification and characterisation of tumour-initiating cells in non-small-cell lung cancer. Eur J Cardiothorac Surg 2009, 36:446-453.

33. Quest Diagnostics: CD117 (c-kit) IHC with interpretation. [http://www. questdiagnostics.com/testcenter/testguide.action?dc=TH_CD117_IHC]

34. Kubo T, Takigawa N, Osawa M, Harada D, Ninomiya T, Ochi N, Ichihara E, Yamane $H$, Tanimoto M, Kiura K: Subpopulation of small-cell lung cancer cells expressing CD133 and CD87 show resistance to chemotherapy. Cancer Sci 2013, 104:78-84.

35. Chen JS, Pardo FS, Wang-Rodriguez J, Chu TS, Lopez JP, Aguilera J, Altuna X, Weisman RA, Ongkeko WM: EGFR regulates the side population in head and neck squamous cell carcinoma. Laryngoscope 2006, 116:401-406.

36. Sussman RT, Ricci MS, Hart LS, Sun SY, El-Deiry WS: Chemotherapy-resistant side-population of colon cancer cells has a higher sensitivity to TRAIL than the non-SP, a higher expression of c-Myc and TRAIL-receptor DR4. Cancer Biol Ther 2007, 6:1490-1495.

37. Sullivan JP, Spinola M, Dodge M, Raso MG, Behrens C, Gao B, Schuster K, Shao C, Larsen JE, Sullivan LA, Honorio S, Xie Y, Scaglioni PP, DiMaio JM, Gazdar AF, Shay JW, Wistuba II, Minna JD: Aldehyde dehydrogenase activity selects for lung adenocarcinoma stem cells dependent on notch signaling. Cancer Res 2010, 70:9937-9948.

38. Clarke RB: Isolation and characterization of human mammary stem cells. Cell Prolif 2005, 38:375-386

39. Kang Y, Omura M, Suzuki A, Oka T, Nakagami Y, Cheng C, Nagashima Y, Inoue T: Development of an orthotopic transplantation model in nude mice that simulates the clinical features of human lung cancer. Cancer Sci 2006, 97:996-1001.

40. Tunér J, Hode L: Laser therapy-clinical practice and scientific background. In Some Basic Laser Physics. AB Grängesberg, Sweden: Prima Books; 2004 $8,12,16,17,21,22$.

41. Peavy GM: Lasers and laser-tissue interaction. Vet Clin North Am Small Anim Pract 2002, 32:517-534.

42. Hawkins D, Abrahamse H: Phototherapy - a treatment modality for wound healing and pain relief. Afr J Biol Res 2007, 10:99-109.

43. Basford JR: Low intensity laser therapy: still not an established clinical tool. Lasers Surg Med 1995, 16:331-342.

44. Matic M, Lazetic B, Polljacki M, Duran V, Ivkov-Simic M: Low level laser irradiation and its effects on repair processes in the skin. Med Pregl 2003, 56:137-141.
45. Stadler L, Lanzafame R, Oskoui P, Zhang R, Coleman J, Whittaker M: Alteration of skin temperature during low level laser irradiation at 830 $\mathrm{nm}$ in a mouse model. Photomed Laser Surg 2004, 22:227-231.

46. Passarella S, Casamassima E, Molinari S, Pastore D, Quagliariello E, Catalano IM: Increase of proton electrochemical potential and ATP synthesis in rat liver mitochondria irradiated in vitro by helium-neon laser. FEBS Lett 1984, 175:95-99.

47. Wan-Ping H, Jeh-Jeng W, Chia-Li Y, Cheng-Che EL, Gow-Shing C, Hsin-Su Y: Helium-neon laser irradiation stimulates cell proliferation through photostimulatory effects in mitochondria. J Invest Dermatol 2007, 127:2048-2057.

48. De Souza SC, Munin E, Alves LP, Salgado MA, Pacheco MT: Low power laser radiation at $685 \mathrm{~nm}$ stimulates stem-cell proliferation rate in Dugesia tigrina during regeneration. J Photochem Photobiol B 2005, 80:203-207.

49. Abrahamse $\mathrm{H}$ : The use of laser irradiation to stimulate adipose derived stem cell proliferation and differentiation for use in autologus grafts, Paper presented at: 7th International Conference on Laser Application; 17-21 May. Cairo: ICLA; 2009. 978-0-7354-0711-4.

50. Hamblin MR, Demidova TN: Mechanisms of low level light therapy. Proc SPIE 2006, 6140:1-12.

51. Gasparyan L, Brill G, Makela A: Influence of low level laser radiation on migration of stem cells [abstract]. Laser Med Sci 2004, 19:S5.

52. Schindl A, Schindl $M$, Schon $H$, Knobler R, Havelec L, Schindl L: Low intensity laser irradiation improves skin circulation in patients with diabetic microangiopathy. Diabetes Care 1998, 21:580-584.

53. Masha RT, Houreld N, Abrahamse H: Low-intensity laser irradiation at 660 $\mathrm{nm}$ stimulates transcription of genes involved in the electron transport chain. Photomed Laser Surg 2013, 31:47-53.

54. Ocana-Quero JM, Gomez-Villamondos R, Moreno-Millan M, SantistebanValenzuela JM: Detrimental effect of low power helium-neon laser irradiation on in vitro meiotic maturation of immature bovine oocytes. Lasers Life Sci 1997, 7:157-166.

55. Pinheiro ALB, Nascimento SC, Veira ALB, Brugnera A, Zanin FA, Rolim DDS, Da Silva PS: Effects of low level laser therapy on malignant cells: in vitro study. J Clin Laser Med Surg 2002, 20:23-26.

56. Maduray $K$, Karsten A, Odhav B, Nyokong T: In vitro toxicity testing of zinc tetrasulfophthalocyanines in fibroblast and keratinocyte cells for the treatment of melanoma cancer by photodynamic therapy. J Photochem Photobiol B 2011, 103:98-104

57. Fedyniak LG: Photodynamic therapy for cancer. Positive Health 2005, 117:24-26.

58. Mallikaratchy P, Tang Z, Tan W: Cell specific aptamer-photosensitizer conjugates as a molecular tool in photodynamic therapy. Chemmedchem 2008, 3:425-428.

59. Stefflova K, Chen J, Zheng G: Using molecular beacons for cancer imaging and treatment. Front Biosci 2007, 12:4709-4721.

\section{$10.1186 /$ scrt340}

Cite this article as: Crous and Abrahamse: Lung cancer stem cells and low-intensity laser irradiation: a potential future therapy?. Stem Cell Research \& Therapy 2013, 4:129 